\title{
Purwarupa Pemisah Tomat Dengan Kamera dan Algoritma K-NN
}

\author{
Daniel S Pamungkas ${ }^{1 *}$, dan Ilham Febrianto ${ }^{1}$ \\ ${ }^{1}$ Politeknik Negeri Batam, Batam, Indonesia \\ *Email: daniel@polibatam.ac.id
}

\begin{abstract}
Abstrak - Kebutuhan manusia terhadap tomat sekarang ini sudah banyak digunakan khususnya di pengolahan makanan sehingga dibutuhkan alat pemisah kematangan tomat.atas dasar ini peneliti membuat alat yang dapat memilah tomat berdasarkan dari warna tomat tersebut. Pada penelitian ini tomat diklasifikasikan dengan cara tomat dimasukkan kedalam lorong yang miring. Lorong ini membawa tomat menuju kamera. Kemudian diambil gambar dan diklasifikasi berdasarkan warna tomat, matang atau tidak mengunakan algoritma K-NN. Kemudian akan menjadi inputan bagi controller untuk memilih akan memasukan ke wadah yang sesuai. Dari hasil penelitian diketahui keberhasilan dari alat ini adalah sebesar $95 \%$ untuk dapat memilah tomat sesuai dengan kematangannya.
\end{abstract}

Kata Kunci: K-NN, klasifikasi, pemisahan, tomat

\section{Pendahuluan}

TOMAT merupakan tanaman sayuran yang berperan penting dalam pemenuhan gizi masyarakat. Tomat merupakan tumbuhan asli Amerika Tengah dan Selatan, dari Meksiko sampai Peru. Menurut Tim Bina Karya Tani, Tomat merupakan buah/sayuran yang sangat dibutuhkan didalam makan. Banyak sekali makanan yang berbahan dasar dari tomat seperti saus dan sambal, tomat bisa juga menjadi pelengkap makanan [1]. Tomat juga memiliki banyak manfaat untuk tubuh manusia seperti berkhasiat untuk mengobati diare, serangan empedu, gangguan pencernaan dan memulihkan fungsi lever.

Jika melihat dipasaran, kita bisa menemukan tomat dengan dua warna, yakni warna merah cerah dan hijau. namun tomat yang baik dikonsumsi adalah tomat merah cerah. Tomat berwarna merah cerah mengandung vitamin $\mathrm{C}$ dan vitamin $\mathrm{A}$ lima kali lebih banyak dibandingkan tomat hijau. Akan lebih baik jika ada suatu alat yang dapat memilah tomat berdasarkan warnanya secara otomatis.

Beberapa penelitian mencoba untuk menklasifikasikan tomat berdasarkan warnanya, Nasution dan Fadilah mengunakan metoda $\mathrm{YCbCr}$ untuk memisahkan tomat berwarna merah, kuning dan hijau [2], sedangkan metoda fuzzy logic juga dicoba digunakan untuk menentukan kematangan tomat mengunakan kamera [3]. Metoda lain juga dicoba oleh Hidayatulloh dan Riyato mengunakan Haar
Cascade dan Color Filtering [4]

Berdasarkan masalah tersebut maka penelitian ini berusaha untuk membuat sebuah prototype alat yang dapat memisahkan tomat yang belum matang dan matang secara otomatis. Alat ini akan dicoba dengan mengunakan algoritma K-Nearest Neighborhood atau dikenal sebagai algoritma K-NN. Pada bab selanjutnya akan dibahas mengenai dasar teori diantranya adalah algoritma K-NN dilanjutkan dengan metoda penelitian. Setelahnya akan diikuti oleh hasil dan kesimpulan.

\section{DASAR TEORI}

\section{A. Pengolahan Citra}

Citra dari segi matematis merupakan fungsi kontinyu berdasarkan intesitas cahaya pada gambar dua dimensi agar dapat diolah dengan menggunakan komputer digital untuk mendapatkan informasi dari sebuah citra. Model warna RGB adalah model warna berdasarkan konsep penambahan kuat cahaya primer yaitu merah, hijau dan biru. Dalam suatu ruang yang sama sekali tidak ada cahaya, maka ruangan tersebut adalah gelap total.

Tidak ada signal gelombang cahaya yang diserap oleh mata atau RGB $(0,0,0)$. Apabila ditambahkan cahaya merah pada ruangan tersebut, maka ruangan akan berubah warna menjadi merah misalnya RGB $(255,0,0)$, semua benda dalam ruangan tersebut hanya dapat terlihat berwarna merah. Demikian apabila cahaya diganti dengan hijau atau biru. Pada perhitungan dalam program-program komputer model warna direpresentasi dengan nilai komponennya, seperti dalam RGB (r, g, b) masing-masing nilai antara 0 hingga 255 sesuai dengan bagian masing-masing yaitu pertama Red, kedua Green dan ketiga adalah nilai Blue dengan demikian masingmasing komponen ada 255 tingkat [5].

\section{B. Algoritma $K-N N$}

Algoritma K-Nearest Neighbor (KNN) adalah sebuah metode untuk melakukan klasifikasi terhadap objek berdasarkan data pembelajaran yang jaraknya paling dekat dengan objek tersebut. Data pembelajaran diproyeksikan k ruang berdimensi banyak, dimana masing - masing dimensi merepresentasikan fitur dari data. Ruang ini dibagi menjadi bagian - bagian berdasarkan klasifikasi data pembelajaran. Sebuah titik pada ruangan ini ditandai dengan kelas c, jika 
kelas c merupakan klasifikasi yang paling banyak ditemui pada $\mathrm{k}$ buah tetangga terdekat titik tersebut. K-Nearest Neighbor merupakan metode yang bersifat supervised, dimana hasil dari query instance yang baru diklasifikasikan berdasarkan mayoritas kategori pada KNN

Pada fase training, algoritma ini hanya melakukan penyimpanan vektor-vektor fitur dan klasifikasi data training sample. Pada fase klasifikasi, fitur-fitur yang sama dihitung untuk testing data (klasifikasinya belum diketahui). Jarak dari vektor yang baru ini terhadap seluruh vektor training sample dihitung, dan sejumlah $\mathrm{k}$ buah yang paling dekat diambil. Titik yang baru klasifikasinya diprediksikan termasuk pada klasifikasi terbanyak dari titik-titik tersebut.

Ketepatan algoritma KNN oleh ada atau tidak adanya fiturfitur yang tidak relevan, atau jika bobot fitur tersebut setara dengan relevansinya terhadap klasifikasi. Algoritma K Nearest Neighbor memiliki kelebihan yaitu dapat menghasilkan data yang kuat atau jelas dan efektif jika digunakan pada data yang besar. Dari beberapa kelebihan tersebut, K-Nearest Neighbor juga memiliki kekurangan yaitu membutuhkan nilai K sebagai parameter, jarak dari data percobaan tidak dapat jelas dengan tipe jarak yang digunakan dan dengan atribut yang digunakan untuk memperoleh hasil yang terbaik, maka harus menggunakan semua atribut atau hanya satu atribut yang telah pasti, dan perhitungan harga sangat tinggi karena percobaan ini membutuhkan perhitungan jarak dari beberapa query untuk semua data percobaan. Adapun algoritma dari KNN ditunjukan pada diagram alir yang terlihat pada gambar 1 .

Algoritma K-NN menggunakan klasifikasi ketetanggaan sebagai nilai prediksi dari sample uji yang baru. Dekat atau jauhnya tetangga biasanya dihitung berdasarkan jarak Eucledian.

$$
\begin{aligned}
& r=\sqrt{\left(q_{1}-p_{1}\right)^{2}+\left(q_{2}-p_{2}\right)^{2}+. .\left(q_{n}-p_{n}\right)^{2}} \\
& r=\sqrt{\sum_{i=1}^{n}\left(q_{i}-p_{i}\right)^{2}}
\end{aligned}
$$

Dimana $\mathrm{q}$ adalah data latih dan $\mathrm{p}$ adalah data uji dengan $\mathrm{n}$ adalah jumlah banyaknya data.

Jarak dihitung pada semua kelas. Jarak kemudian diurutkan dari yang terdekat sampai yang terjauh untuk semua data dan semua kelas. Kemudian berdasarkan nilai tersebut dilihat $\mathrm{K}$ (nilai ganjil dipilih salah satu: 1,3,5 dst) data. $\mathrm{K}$ nilai teratas yang ada dilihat yang paling banyak kelasnya. Kelas yang terbanyak itulah hasil klasifikasi algoritma K-NN [6], hal tersebut dapat dilihat pada gambar 1 .

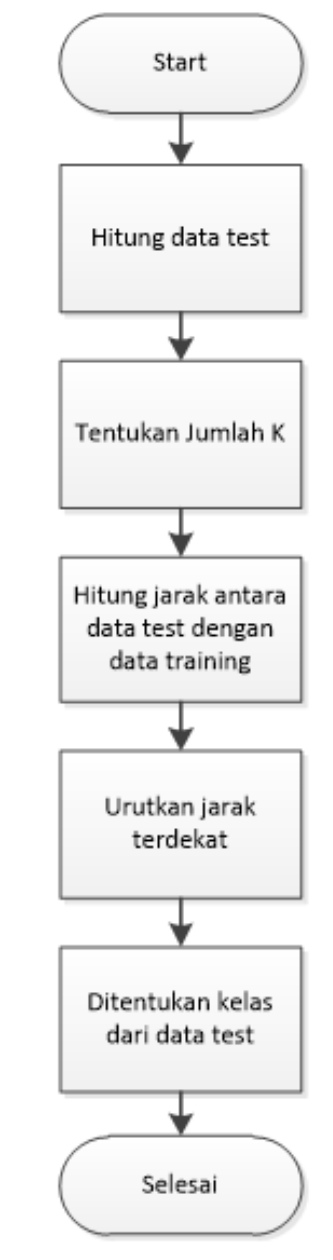

Gambar 1. Flow chart K-NN

\section{Metode}

Pada perancangan peneliti mengunakan satu buah papan inspeksi sederhana yang digunakan sebagai media untuk meletakkan tomat yang akan dideteksi. Pada perancangan perangkat keras yang akan dibuat terdiri dari sebuah kamera webcam, sebuah komputer, sebuah pengendali, Tiga buah motor servo dan papan sebagai tempat peletakan tomat. Dimana kamera webcam yang digunakan adalah sebuah kamera Logitech C270 yang mempunyai resolusi tampilan 720p dengan 30 frame per second.

Motor servo pertama digunakan untuk mendorong tomat turun dari corong. Kemudian tomat ditahan oleh motor servo kedua. Ditempat ini sebuah tomat akan dideteksi oleh sebuah kamera. Ketika hasil klasifikasi tomat sudah didapatkan maka penghalang akan terbuka oleh motor 2 dan motor servo 3 akan mengarahkan tomat ke bagian yang sesuai dengan hasil yang didapatkan.

Berikut adalah blok diagram dari perancangan perangkat keras yang akan dirancang dapat dilihat pada gambar 2 Sedangkan gambar 3 mengambarkan sistem yang digunakan untuk percobaan dengan penjelasan seperti pada paragraph sebelumnya. Gambar 4 menunjukan diagram alir dari sistem yang diusulkan. 


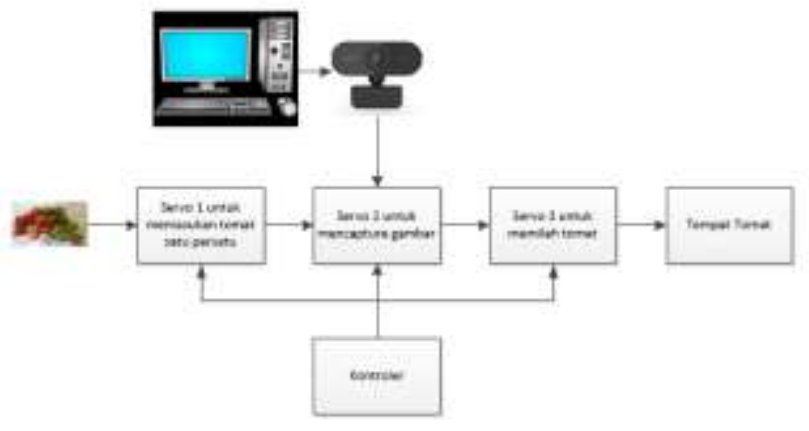

Gambar 2. Blok diagram sistem

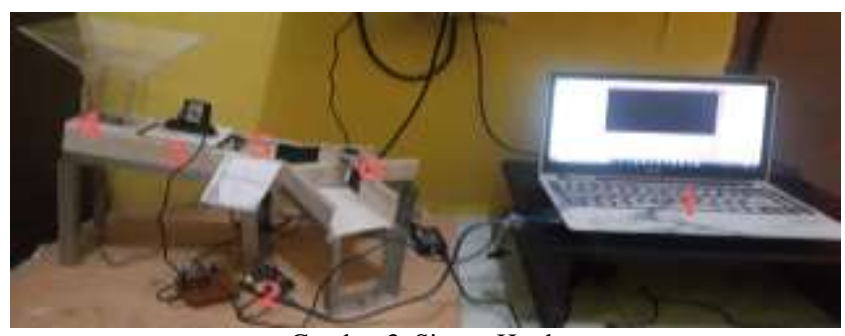

Gambar 3. Sistem Hardware

Ket : 1. Laptop, 2. Arduino, 3. Kamera, 4. motor servo 5. motor servo 2,6 . motor servo 3

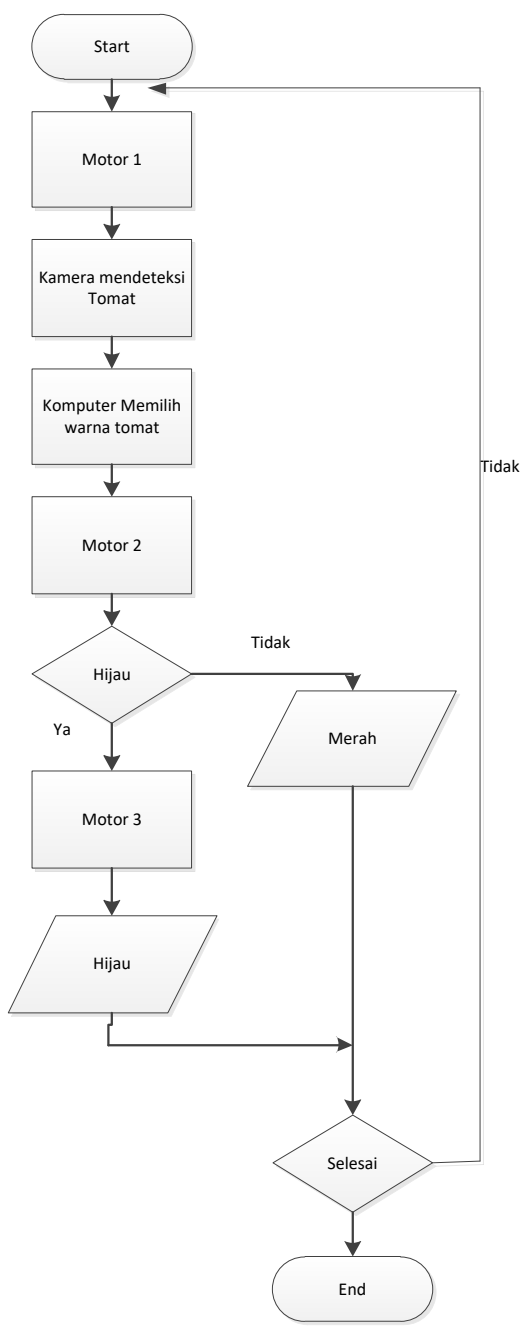

Gambar 3. Diagram alir proses

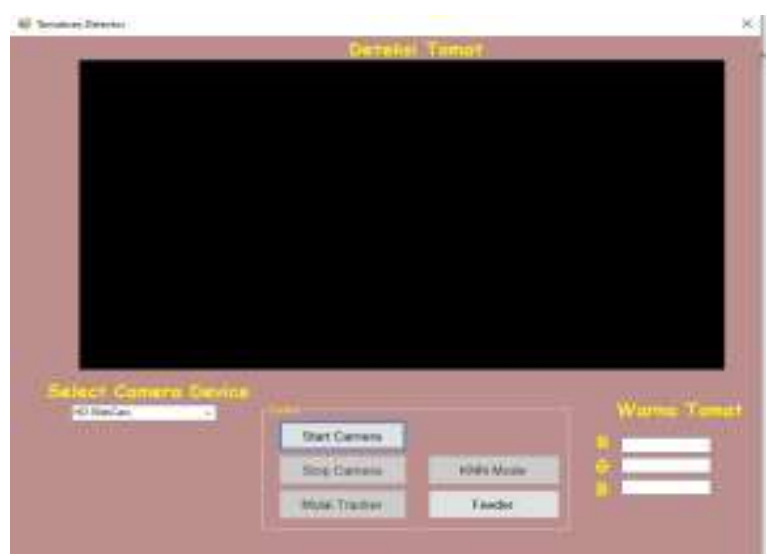

Gambar 4. Tampilan GUI

Sedang diagram alir dari system dapat dilihat pada gambar 5. Dimana digunakan dua fasa yaitu fase pelatihan dan fasa uji. Difasa pelatihan, data-data akan disimpan sebagai data pelatihan. Setiap tomat akan dilihat setiap komponen RGBnya. Data ini akan dipakai di fasa uji. Dimana setiap tomat yang akan diuji dilihat komponen RGBnya kemudian dihitung jarak Eucledian berdasarkan persamaan (1).

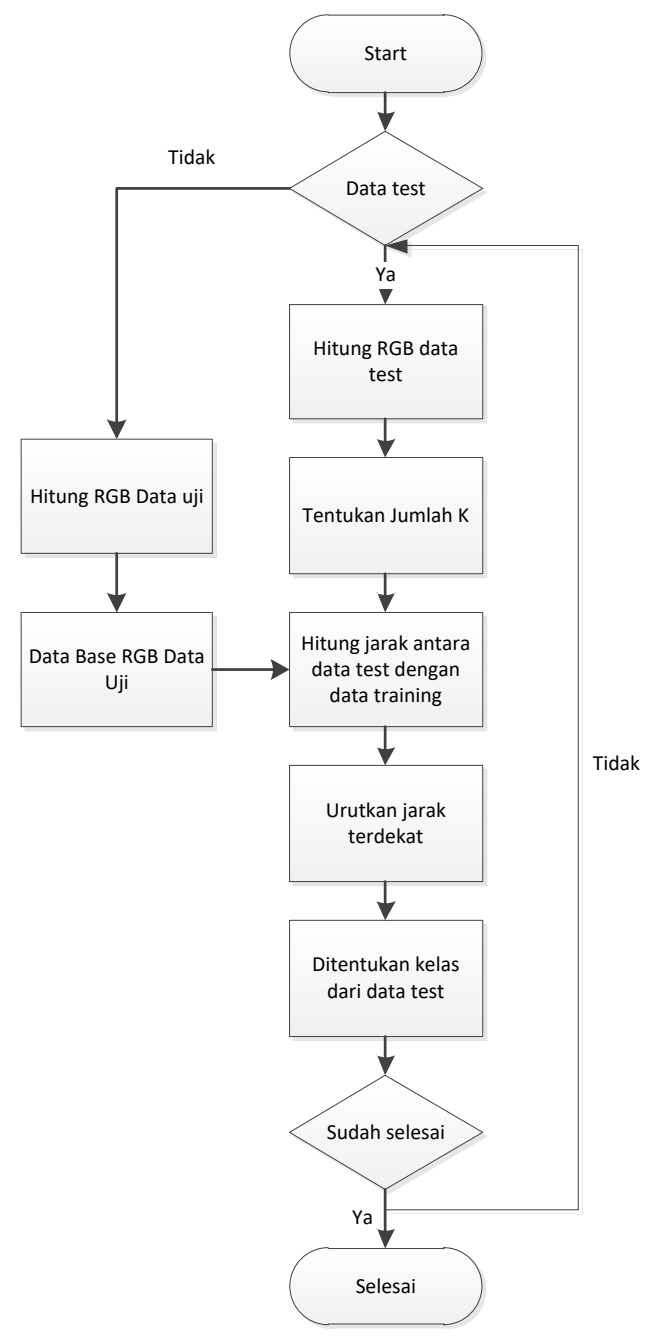

Gambar 5. Diagram alir sistem 


\section{HASIL DAN PEMBAHASAN}

Untuk percobaan digunakan 20 tomat merah dan 20 tomat hijau. Dimana tomat-tomat tersebut akan dibagi dua menjadi 20 buah tomat hijau dan merah sebagai tomat untuk pelatihan. Sedangkan sisanya digunakan untuk test, dimana 10 tomat baik merah dan hijau yang digunakan. Gambar 6 adalah gambar tomat yang digunakan untuk uji.

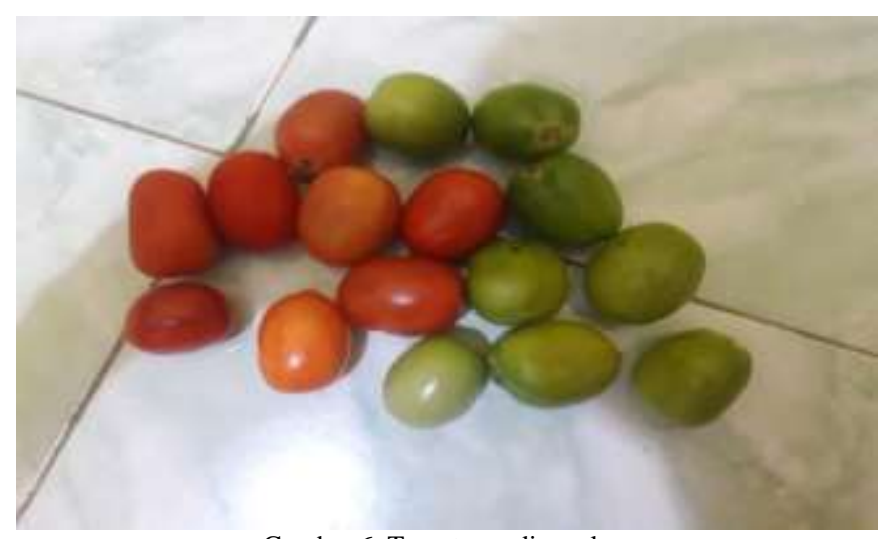

Gambar 6. Tomat yng digunakan

Dengan mengunakan $\mathrm{K}=3$ maupun $\mathrm{K}=5$, alat mampu mendeteksi dan memisahkan tomat yang berwarna hijau sebanyak $100 \%$ sedangkan yang berwarna merah terdapat satu buah tomat yang terdeteksi salah. Sehingga total rata-rata persentasi keberhasilan mengunakan alat ini adalah $95 \%$.

\section{KESIMPULAN}

Prototype yang diusulkan mampu memisahkan tomat dengan keberhasilan 95\%. Selanjutnya akan dicobakan untuk memisahkan tomat dengan berbagai warna yang menandakan kematangan dari buah tomat.

\section{PENGHARGAAN}

Penghargaan ditujukan kepada Politeknik Negeri Batam yang telah menyediakan sarana untuk penelitian ini.

\section{REFERENSI}

[1] Yrama Widya, "Pedoman Bertanam Tomat", Bandung, Tim Bina Karya Tani. 2009..

[2] M. S. Nasution dan N. Fadilah., "Deteksi kematangan buah tomat berdasarkan warna buah mengunakan metoda YCbCr" InfoTekJar, Vol3 no $2,2019$.

[3] N. Muhtiadi, H. Herlinawati, S. R. Sulistiyanti, dan S. Purwiyanti., "Deteksi Tingkat Kematangan Buah Tomat dengan Metode Fuzzy Logic Menggunakan Modul Kamera Raspberry PI", electrician Vol 13 no 2, 2019

[4] A. Hidayatulloh dan I. Riyanto., "Rancang Bangun Prototype Penyortir Buah Tomat Berdasarkan Kematangan mengunakan Image Processing" Jurnal Maestro Vol 1. No1 2018

[5] A. A. Saputra, R. R. M and C. Setianingsih, "Perancangan dan Implementasi Alat untuk Penyortiran Buah Tomat (Lycopersicum Esculentum) Menggunakan Mikrokomputer," e-Proceeding of Engineering, vol. 4, no. 3, ISSN: 2355-9365, pp. 4074-4082, 2017.

[6] R. T. P and M., "Klasifikasi Mutu Telur Berdasarkan Kebersihan Kerabang Telur Menggunakan K-Nearest Neighbor," in Konferensi Nasional Informatika (KNIF) 2015, pp. 241-245, 2015. 